Dossier: Poesía, armonía y conflictos: ayer y hoy

\title{
A guerra é aqui: considerações sobre a poesia brasileira em tempos de crise
}

\author{
Vera Lúcia de Oliveira \\ Università degli Studi di Perugia, Italia. \\ vera.deoliveira@unipg.it \\ https://orcid.org/0000-0002-1323-3140
}

Recibido: 1 de agosto de 2019

Aceptado: 20 de setiembre de 2019

Resumo: Partindo do tema do evento, realizado pela Universidade Nova de Lisboa, em outubro de 2017, esboço uma reflexão sobre o trinômio "poesia, paz e guerra" a partir da situação da sociedade brasileira atual, que perde rapidamente algumas das conquistas democráticas obtidas nos últimos vinte anos. Como os poetas brasileiros vivem esse momento, como se relacionam com ele? Para responder, concentrei-me numa rápida análise de alguns poemas de Donizete Galvão.

Palavras chave: poesia brasileira; poesia contemporânea; poesia e crise; poesia, paz e guerra; Donizete Galvão.

\section{The war is here: considerations on brazilian poetry in times of crisis}

Abstract: Starting from the theme of the event, held by the Universidade Nova de Lisboa in October 2017, I outline a reflection on the trinomial "poetry, peace and war" based on the current Brazilian society, which rapidly loses some of the democratic achievements twenty years. How do Brazilian poets live this moment, how do they relate to it? To answer, I concentrated on a quick analysis of some poems by Donizete Galvão.

Keywords: Brazilian poetry; contemporary poetry; poetry and crisis; poetry, peace and war; Donizete Galvão.

\section{(C) $(00$}

La Revista Estudios es editada por la Universidad de Costa Rica y se distribuye bajo una Licencia Creative Commons Atribución-NoComercial-CompartirIgual 3.0 Costa Rica. Para más información envíe un mensaje a 


\section{Dossier: Poesía, armonía y conflictos: ayer y hoy}

Quando fui convidada para esse simpósio, "Poesia, paz e guerra”, pensei que a associação desses três termos, dessas três realidades, era não só pertinente, mas arguta e apropriada. A guerra é um tempo e um espaço de confim, onde se confunde e, por vezes, se dissolve a fronteira entre o bem e o mal, entre a vida e a morte. Nesse limite, a palavra se esgarça, a língua gagueja, a fala se perde entre a indiferença, a incompreensão e a anulação do sujeito que por ventura fosse ainda capaz de articular uma linguagem.

Nessa zona limítrofe, a dor, o horror e a morte cancelam a testemunha e nulificam a possibilidade que se possa entender, pelo lado de dentro, o atravessamento dessa fronteira entre o humano e o não-humano. Em um penetrante ensaio sobre Primo Levi, Giorgio Agamben afirma, comentando os livros em que Levi narra sua experiência no campo de concentração de Auschwitz:

“La šo'ah è un evento senza testimoni nel duplice senso che di essa è impossibile testimoniare tanto dallinterno - perché non si può testimoniare dallinterno della morte - non vi è voce per lo svanire della voce - quanto dall'esterno - perché l'outsider è escluso per definizione dall'evento". (AGAMBEN, 2010, pp. 32-33)

[A šo'ah é um evento sem testemunhas, no duplo sentido de que é impossível testemunhar, quer a partir de uma ótica interna - porque não se pode testemunhar por dentro da morte - não há voz para o desaparecimento da voz - quer externa - porque o outsider é, por definição, excluído do evento. $]^{1}$

\footnotetext{
${ }^{1}$ As traduções, quando não indicado diversamente, são de minha autoria.

\section{(c) (i) (2)(2)}

La Revista Estudios es editada por la Universidad de Costa Rica y se distribuye bajo una Licencia Creative Commons Atribución-NoComercial-Compartirlgual 3.0 Costa Rica. Para más información envíe un mensaje a revistaestudios.eeg@ucr.ac.cr.
} 


\section{Dossier: Poesía, armonía y conflictos: ayer y hoy}

Há um hiato, portanto, há um espaço preclusivo à palavra e, contudo, ainda humano, em que uma linha é atravessada, mas quem passa não leva a linguagem e, em algum momento, que desconhecemos, ela é deixada para trás.

Onde ficam as palavras de quem supera o limite da vida? Onde ir buscá-las? Elas se perdem no vento?, elas se congelam na boca de quem cai, quer seja em um atentado, quer numa ação de guerra? Elas vagam como sementes que não germinam porque não há solo capaz de contê-las?

Nesse limite chega o poeta, o poeta verdadeiro, para o qual a consciência é campo de pesquisa e indagação, é o lugar enigmático e arcano que ele busca desesperadamente habitar e elucidar, muitas vezes ferindo-se mortalmente nessa perquirição. Desde sempre a linguagem da fronteira entre o dizível e o indizível foi a poesia. O poeta habita o mundo com todos os sentidos, empurra com o próprio corpo portas que não se abrem à razão, perscruta espaços obscuros, caminha pelas bordas do mistério humano: "A poesia é, de fato, uma forma de conhecimento muito profunda. O poeta parte para a sua viagem num pequeno barco de papel, jogado por todas os lados dentro e fora da alma. Às vezes, no meio da viagem, naufraga, ou então se adentra por um pedaço desconhecido de mar." (OLIVEIRA, 2017, p. 102)

Quantos poetas narraram experiências extremas e viscerais, quantos nos descortinaram universos nos quais tememos entrar? A urgência de testemunhar acompanha a grande poesia e é sempre Primo Levi que nos ajuda a entender a função catártica dela, que, pela beleza, nos permite entrar e sair dos espaços de silenciamento do humano. Sobrevimente de Auschwitz, tendo que lidar com a memória do que tinha vivido e não podendo ainda narrá-la, é a poesia que o salva: "Scrivevo poesie concise e sanguinose, raccontavo con vertigine, a voce e per scritto, tanto che poco a poco nacque poi un libro: scrivendo trovavo breve pace e mi sentivo ridiventare uomo". (LEVI, 1987, p. XLV). [Escrevia poemas concisos e ensanguentados, narrava com vertigem, em voz alta ou por escrito, tanto que,

La Revista Estudios es editada por la Universidad de Costa Rica y se distribuye bajo una Licencia Creative Commons Atribución-NoComercial-CompartirIgual 3.0 Costa Rica. Para más información envíe un mensaje a 


\section{Dossier: Poesía, armonía y conflictos: ayer y hoy}

pouco a pouco, nasceu um livro: escrevendo, encontrava breve paz e sentia que voltava de novo a ser um homem.]

Experiências como essas permitem que possamos resgatar momentos da história que conhecemos apenas porque grandes escritores puderam adentrar-se na alteridade de quem não teve acesso à voz e à palavra. $O$ historiador pesquisa em arquivos e usa documentos, o jornalista descreve fatos e testemunha com relatos e fotos o vivido, mas há um vazio que só pode ser ocupado pela sensibilidade e pela capacidade empática do artista e do poeta.

O tema, assim, me apaixonou desde o início. No entanto, foi-me solicitado aqui que o declinasse em relação à poesia brasileira. E comecei a pensar em quantos poetas brasileiros refletiram, em seus versos, sobre a primeira ou a segunda guerra mundiais: Carlos Drummond de Andrade em A rosa do povo, livro de 1945, Murilo Mendes em Poesia liberdade, de 1947, ou mesmo Cassiano Ricardo que, em Jeremias Sem-chorar, de 1964, capta já também a sensação de precariedade de um mundo ameaçado pela bomba atômica.

Andando pelas ruas de São Paulo, em agosto de 2017, continuava a pensar em como traçar uma linha de continuidade entre esses e outros poetas que viveram os anos trágicos das guerras na Europa, quando me deparo, de baque, como o real, com o cotidiano do meu país. E me veio à alma uma indignação e uma revolta em ver o retrocesso rápido que é imposto a um povo que ousou sonhar que o futuro fosse hoje, que era possível construir uma nação mais justa, que era possível erradicar a fome, que era possível que brancos, negros, índios e gente de todas as cores e origens pudessem conviver.

A guerra era ali, pensei, a guerra era ao meu redor, a guerra era a daquele homem que constrói com caixas de papelão uma espécie de oca em plena Avenida Paulista, que é a mais rica da cidade, para suportar o frio das noites invernais de São Paulo, a guerra é a do mendigo que me pára e pede ajuda para comprar um lanche, a guerra é a de quem é trucidado nas periferias só porque é

La Revista Estudios es editada por la Universidad de Costa Rica y se distribuye bajo una Licencia Creative Commons Atribución-NoComercial-CompartirIgual 3.0 Costa Rica. Para más información envíe un mensaje a 


\section{Dossier: Poesía, armonía y conflictos: ayer y hoy}

negro ou pobre, a guerra é a de quem rouba para comprar um remédio para o filho, é a de quem é expulso de novo de volta à favela, é a de quem vive nas sarjetas de um dos países mais ricos do mundo.

A guerra é aqui, pensei, o "Haiti é aqui", como afirma Caetano Veloso, na música "Haiti", do disco "Tropicália 2", de 1993. O Haiti era apontado, nos anos noventa, como um dos países com maior desigualdade social e violência do mundo. Os dois artistas, Caetano Veloso e Gilberto Gil, no entanto, chamam a atenção para o fato que a realidade brasileira era tão injusta e violenta quanto a do Haiti e que havia em todas as cidades do país bolsões de miséria e discriminação, como a que levou ao massacre do Carandiru, em que 111 presos foram assassinados quando a Polícia Militar de São Paulo interveio para conter uma rebelião, ocorrida em 2 de outubro de 1992, na Casa de Detenção do Carandiru. Assim diz a música:

"E quando ouvir o silêncio sorridente de São Paulo

Diante da chacina

111 presos indefesos, mas presos são quase todos pretos

Ou quase pretos, ou quase brancos quase pretos de tão pobres

E pobres são como podres e todos sabem como se tratam os pretos

$(\ldots)$

Pense no Haiti, reze pelo Haiti

O Haiti é aqui"

(VELOSO, GIL, 1993)

A história brasileira é uma história de conflitos perenes e o processo de formação desse povo-nação é definido por Darcy Ribeiro (1922-1997) como um "moinho de gastar gente" (RIBEIRO, 1995, p. 106). Afirma Darcy Ribeiro, em um

\section{c) (i) (2)}

La Revista Estudios es editada por la Universidad de Costa Rica y se distribuye bajo una Licencia Creative Commons Atribución-NoComercial-CompartirIgual 3.0 Costa Rica. Para más información envíe un mensaje a 


\section{Dossier: Poesía, armonía y conflictos: ayer y hoy}

texto escrito quando retornou ao Brasil depois de doze anos de exílio por vários países, ao se deparar com o rastro deixado pela ditadura:

"O Brasil jamais existiu para si mesmo, no sentido de produzir o que atenda aos requisitos de sobrevivência e prosperidade de seu povo. Existimos é para servir a reclamos alheios. Por isso mesmo, o Brasil sempre foi, e ainda é, um moinho de gastar gentes." (RIBEIRO, 2010, pp. 24-25)

O próprio processo formativo da sociedade brasileira produziu a estratificação social hodierna, separando, desde o início, a Casa Grande da Senzala, os ricos dos pobres, os brancos dos índios, negros e mestiços. E para quem cultivasse a ideia romântica de que no Brasil nunca houve guerra, é ainda o lúcido e contundente Darcy Ribeiro, no livro O povo brasileiro, de 1995, a pôr abaixo essa versão de cômodo:

"O povo brasileiro pagou, historicamente, um preço terrivelmente alto em lutas das mais cruentas de que se tem registro na história, sem conseguir sair, através delas, da situação de dependência e opressão em que vive e peleja. Nessas lutas, índios foram dizimados e negros foram chacinados aos milhões, sempre vencidos e integrados nos plantéis de escravos." (RIBEIRO, 1995, p. 25)

A literatura brasileira manteve e mantém uma relação forte com a sociedade e, neste sentido, Wilson Martins afirma que ela é mais sociológica do que psicológica (MARTINS, 1968, pp. 119-120). O escritor desde o inicio assumiu a responsabilidade ética de pensar o seu país, de definir o que era o Brasil e quem era essa nova gente, gerada do encontro-desencontro de povos tão diferentes.

\section{(c) (i) (2)}

La Revista Estudios es editada por la Universidad de Costa Rica y se distribuye bajo una Licencia Creative Commons Atribución-NoComercial-CompartirIgual 3.0 Costa Rica. Para más información envíe un mensaje a 


\section{Dossier: Poesía, armonía y conflictos: ayer y hoy}

Já no Romantismo José de Alencar (1829-1877) reafirma que o intelectual no Brasil tem uma grande responsabilidade em relação à sociedade. Em 1874, polemicamente, escrevia Alencar:

"Enquanto em Portugal, sem darem-se ao trabalho sequer de ler-nos, acusavam-nos de abastardar a língua, de enxovalhar a gramática; nós ao contrário, apreciando as melhores obras portuguesas, aprendíamos na diversidade dos costumes e da índole a formar essa literatura brasileira, cuja independência mais se pronuncia de ano em ano." (ALENCAR, 1993, p. 59)

Essa relação forte com a sociedade e com a história leva Gonçalves Dias (1823-1864), outro grande autor do nosso Romantismo, a pôr-se na pele do índio defraudado do seu universo, espoliado de sua religião e cultura. E cito aqui, entre seus poemas indianistas, "Deprecação", em que um índio se dirige a Deus, interpelando-o com desespero sobre a as causas do silêncio e abandono por parte do criador e sobre porque permite que invadam e assolem as terras indígenas:

"E a terra em que pisam, e os campos e os rios

Que assaltam, são nossos; tu és nosso Deus:

Por que Ihes concedes tão alta pujança, Se os raios de morte, que vibram, são teus?" (GONÇALVES DIAS, 1974, pp. 65-66)

Essa mesma relação com a sociedade se manteve nos anos modernistas, em que vemos um Oswald de Andrade (1890-1954), no livro Pau-Brasil, de 1925, resgatar em poemas densos e concisos toda a trágica violência da escravidão, na seção "Poemas da colonização":

\section{(c) (i) (2) (-)}

La Revista Estudios es editada por la Universidad de Costa Rica y se distribuye bajo una Licencia Creative Commons Atribución-NoComercial-CompartirIgual 3.0 Costa Rica. Para más información envíe un mensaje a 
Dossier: Poesía, armonía y conflictos: ayer y hoy

medo da senhora

A escrava pegou a filhinha nascida

Nas costas

E se atirou no Paraíba

Para que a criança não fosse judiada

(ANDRADE, 1974, p. 94)

São histórias de vidas de mulheres anônimas, muitas vezes meninas, que pela poesia retornam com suas vozes, cuja dor não permite que nem com a morte elas se possam libertar do jugo, como no poema "caso":

A mulatinha morreu

E apareceu

Berrando no moinho

Socando pilão

(ANDRADE, 1974, p. 93)

E hoje, onde estão os poetas, eu me perguntava, olhando ao meu redor a cidade voraz, que se expande dia e noite, redesenha suas formas, fragmenta bairros, expulsa cada vez mais longe o povo das periferias? Acaso os poetas caminham pelas mesmas calçadas? Ou estão encastelados em suas bibliotecas, submersos pelo trabalho acadêmico, nas redações dos jornais, nas repartições públicas? São capazes de colher o ser em sua nua e penosa indigência?

Vieram-me em mente então tantos nomes, alguns conhecidos, outros menos. Apesar de não ter mais função ou lugar nessa sociedade, a poesia teima e resiste, caminha e frequenta lugares escusos e angustos, se debruça sobre 0 difícil cotidiano de tantos brasileiros. Não digo que todos os poetas

\section{(c) (i) (2) (2)}

La Revista Estudios es editada por la Universidad de Costa Rica y se distribuye bajo una Licencia Creative Commons Atribución-NoComercial-Compartirlgual 3.0 Costa Rica. Para más información envíe un mensaje a 


\section{Dossier: Poesía, armonía y conflictos: ayer y hoy}

contemporâneos reflitam sobre tais questões ou se relacionem com o mundo desta forma visceral, ou que abordem os conflitos que se acirram por todo o país, mas certamente alguns dos que considero fundamentais o fazem, como Donizete Galvão, Conceição Evaristo, Luiz Ruffato, Orides Fontela, Fábio Weintraub, Alexandre Pilati, Ricardo Aleixo, Tarso de Melo, André Luiz Pinto, Dalila Teles Veras e outros.

Não podendo falar de todos, limito-me aqui a Donizete Galvão (1955-2014), poeta e amigo que partiu tão cedo e que tem uma sensibilidade vibrátil e aguçada e uma atenção perenemente voltada para as figuras às margens, os descartados, os expulsos como parias, porque pobres, doentes, velhos, feios, porque não conseguem se adequar à imagem e ao papel que se exige deles, ou porque ousam reivindicar algo mais, como no poema "O asfalto, enfim", em que o corpo do menino morto foi abandonado em um carrinho de construção:

"Se toda morte é descida,

a morte mais dolorida

é aquela com o corpo

varado de balas

$$
\text { debruçado }
$$

sobre o carrinho de construção

que desce as valas da favela.

Morte de cabeça para baixo

como deveria ter sido a vida

inteira

do moleque teimoso

que à força da bala

quis levantá-la do chão."

(GALVÃO, 2010, p. 49)

La Revista Estudios es editada por la Universidad de Costa Rica y se distribuye bajo una Licencia Creative Commons Atribución-NoComercial-Compartirlgual 3.0 Costa Rica. Para más información envíe un mensaje a 
Donizete Galvão nota e anota as vidas minúsculas, que resgata com sua poesia, como a do homem parado num semáforo, perdido em sua solidão, quase alheio ao mundo ao redor, como alheia é a cidade que o ignora, no poema "Roedor":

"Parado no trânsito da Marginal, vi você roendo as unhas com fúria.

Estava encostado no poste da esquina, ombros arqueados numa posição frouxa.

Você cuspia os tocos das unhas.

Arrancava lascas de carne dos dedos

e, depois, sugava o sangue dos cantos.

Ah, que triste figura você fazia, amigo!

Você era pouco mais que um rato."

$$
\text { (GALVÃO, 1997, p. 31) }
$$

Galvão representa, com uma linguagem enxuta, incisiva e priva de retórica, a guerra surda, que se intensifica, contra inteiras faixas da população brasileira. Essa guerra levou à destituição, em 31 de agosto de 2016, da Presidenta Dilma Rousseff, por alegado crime de responsabilidade, por ter assinado em sua gestão, em 2015, um decreto de suplementação orçamentária sem a prévia autorização do Senado. O mesmo Senado Federal, dois dias depois da destituição da Presidenta, votou nova lei, que permite que, a partir de então, tal procedimento não seja mais crime. A Lei 13.3332/2016, sancionada em 02/09/2016, de fato, estipulou novas regras de orçamento, o qual poderá a partir de então ser alterado sem a aprovação do Congresso. Ou seja: o que foi crime para Dilma, não o é para 0 atual presidente e nem para os presidentes vindouros.

\section{(c) (i) (2) (2)}

La Revista Estudios es editada por la Universidad de Costa Rica y se distribuye bajo una Licencia Creative Commons Atribución-NoComercial-CompartirIgual 3.0 Costa Rica. Para más información envíe un mensaje a 


\section{Dossier: Poesía, armonía y conflictos: ayer y hoy}

Com essa crise institucional, em pouco tempo os brasileiros perderam conquistas que levaram quinhentos anos para obter e o país despencou dezenove posições no ranking mundial de desigualdade social. Uma das primeiras medidas do governo de Michel Temer, que assumiu o poder depois do impeachment, foi o corte de cerca de um milhão de cadastros do bolsa-família, um dos programas sociais mais bem sucedidos dos últimos governos de Luiz Inácio Lula da Silva e Dilma Rousseff. Criado em 2004, é um benefício concedido a famílias em situação de extrema pobreza e tinha como pré-requisito que as famílias interessadas vacinassem os filhos e garantissem uma frequência escolar de crianças e adolescentes entre 6 a 15 anos de pelo menos $85 \%$. Tal programa tirou das ruas e do mundo do trabalho milhares de crianças, que tiveram acesso à escola.

Em geral, as medidas neoliberistas do atual governo determinam ingentes cortes nas receitas públicas destinadas à saúde, previdência, assistência social e educação. $O$ cientista político Marcus lanoni afirma que se quer assim

"minimizar o Estado e maximizar o mercado. Isso significa minimizar a democracia e maximizar o controle da esfera política pelos interesses dos investidores financeiros. (...) $\mathrm{O}$ objetivo é retomar o modelo neoliberal de capitalismo (...). Esse modelo tem sido responsável por baixas taxas de crescimento, aumento da desigualdade, redução drástica das políticas de bem-estar social (...)." (IANONI, 2016)

O mesmo programa liberista levou à aprovação de uma reforma drástica da Constituição brasileira de 1988, uma reforma que congela pelos próximos vinte anos justamente o orçamento da educação e saúde. É uma luta, essa, como vemos, contra uma idéia mais inclusiva de sociedade e de nação. Basta ver o que aconteceu em São Paulo, onde o prefeito João Dória, com várias medidas discutíveis, implantou o programa "Cidade limpa", onde o termo "limpo" aqui se

La Revista Estudios es editada por la Universidad de Costa Rica y se distribuye bajo una Licencia Creative Commons Atribución-NoComercial-Compartirlgual 3.0 Costa Rica. Para más información envíe un mensaje a 


\section{Dossier: Poesía, armonía y conflictos: ayer y hoy}

entende também do ponto de vista social, com a dispersão das ruas centrais dos moradores de rua. Em julho, nas noites mais frias do ano, mendigos foram acordados por jatos de água fria em plena madrugada.

O Haiti é aqui, portanto, e ao poeta, expulso da república desde os tempos de Platão, não resta que aguçar os ouvidos, dobrar a atenção, revistar nos restos, recolher os escombros, salvar o usado e o abusado, deter, se possível, o momento em que um corpo desaba, como no poema "Night windows", de Donizete Galvão:

“O quarto está deserto.

Uma das janelas está aberta.

O vento suga a cortina branca para fora da casa.

Alguém está por um fio.

Alguém aposta sua última ficha.

Um corpo cairá no negrume da noite."

$$
\text { (GALVÃO, 2010, p. 26) }
$$

O eu lírico, desperto e atento, ouve aqui até o mínimo rumor de alguém entrando na morte. Desde o primeiro livro, Azul navalha, publicado em 1988, a poesia de Donizete Galvão centrou-se naquelas vidas que Zygmunt Bauman define como as "vidas descartadas" (BAUMAN, 2011).

Tendo nascido em uma pequena cidade de Minas Gerais, em Borda da Mata, embora habitasse há muito em São Paulo, o poeta viveu a cidade sempre com estranhamento. Em O homem inacabado, de 2010, o último publicado em vida por ele, esse estranhamento dá os frutos mais incisivos. O poeta parece em trincheira, em uma guerra não declarada abertamente, mas não menos mortal. O eu lírico chama a atenção para o que está prestes a ser engolido pelo usa-descarta do

\section{(c) (i) (2)}

La Revista Estudios es editada por la Universidad de Costa Rica y se distribuye bajo una Licencia Creative Commons Atribución-NoComercial-Compartirlgual 3.0 Costa Rica. Para más información envíe un mensaje a 


\section{Dossier: Poesía, armonía y conflictos: ayer y hoy}

consumismo, os expulsos de todas as periferias, os párias banidos porque perderam a validade, como se fossem mercadorias.

Nesse livro, o poeta perscruta, até o fundo, uma cidade hostil e um país que Ihe parece estrangeiro, um mundo "que Ihe minara o osso", quase em contraponto dialógico com a metáfora de Darcy Ribeiro, do país como um moinho que esmiúça gente em suas engrenagens. O escritor, de fato, para ver melhor, "entra na fenda, / vai entre as brenhas, / tateia a pedra fria, / vagueia entre frestas, / limos e arestas." (GALVÃO, 2010, p. 23) Para colher o que nessa trincheira? Para catar, ele afirma, "a palavra perdida / na caçamba de entulhos / entre cacos de azulejos / e restos de reboco." (GALVÃO, 2010, p. 32) Sobretudo, interessa-Ihe, como se lê no poema "A aparição dos objetos",

"Tirar do ciclo da morte

aquilo que tantos desprezam -

restos, trapos, cordas,

estrados de cama e roupas sujas -

e fazer com que na tela

nova realidade se revele.

Embebidas de tinta,

os objetos em sua humildade

ganham outra manifestação.

Renomeados pelo olhar,

pelas mãos do pintor

estão para sempre

consagrados."

(GALVÃO, 2010, p. 40)

La Revista Estudios es editada por la Universidad de Costa Rica y se distribuye bajo una Licencia Creative Commons Atribución-NoComercial-CompartirIgual 3.0 Costa Rica. Para más información envíe un mensaje a revistaestudios.eeg@ucr.ac.cr.
} 


\section{Dossier: Poesía, armonía y conflictos: ayer y hoy}

Re-consaguar o entulho, o detrito, a pessoa-coisa, a PESSOA, é esforço de quem se arrisca e se expõe, buscando salvar algum companheiro de jornada, alguém sumindo, alguém sendo privado da identidade, alguém sendo anulado. No poema que dá título ao livro, lemos:

"Nesta cidade impermanente,

um homem jamais está inteiro.

Parte perdeu-se em alguma rodovia.

(...)

Nesta cidade dividida,

Cada homem é estilhaço,

Entulho jogado na caçamba

Porque há outro na fila

Para ocupar o seu espaço."

(GALVÃO, 2010, p. 61)

Afirmou o Papa Francesco, em julho de 2016, em uma entrevista concedida quando retornava de Cracóvia, na Polônia:

"Il mondo è in guerra, guerra a pezzi. C'è stata quella del 1914, con i suoi metodi, poi quella del 1939-45 e adesso questa. (...) Non è tanto organica, ma organizzata si. (...) Quando parlo di guerra intendo guerra sul serio, non di guerra di religione. Parlo di guerre di interessi, per soldi, per le risorse della natura, per il dominio dei popoli. (...) Le religioni - ha concluso tutte le religioni, vogliono la pace. La guerra la vogliono gli altri." (PAPA FRANCESCO, in VECCHI, 2016)

\section{(C) $(\Theta \odot$}

La Revista Estudios es editada por la Universidad de Costa Rica y se distribuye bajo una Licencia Creative Commons Atribución-NoComercial-CompartirIgual 3.0 Costa Rica. Para más información envíe un mensaje a 


\section{Dossier: Poesía, armonía y conflictos: ayer y hoy}

[O mundo está em guerra, guerra aos pedaços. Houve a guerra de 1914, com seus métodos, depois a de 1939-1945 e agora essa. (...) Não é tão orgânica, mas é muito bem organizada, isto sim. (...) Quando falo de guerra, quero dizer guerra de verdade, não de guerra de religião. Estou falando de guerra por interesses, por dinheiro, pelos recursos da natureza, pelo domínio dos povos. (...) As religiões - concluiu ele - todas as religiões, querem paz. A guerra, são outros que a querem.]

A guerra é onde nos roubam o pouco de democracia obtida, onde saqueiam as terras indígenas, onde derrubam florestas, onde cancelam esperanças e perspectivas dos jovens, onde humilham, excluem, fragmentam e fazem com que nos sintamos sempre em culpa por nunca estarmos à altura do mercado, não importa quanto esforço façamos. Tudo isso é colhido pela poesia de Donizete Galvão. Na lírica "Depreciação", há uma inversão até mesmo da máxima divina, que, ao condenar o homem a viver do seu trabalho, Ihe deu em troca a dignidade:

"De hoje em diante

não irás ganhar o pão

com o suor do teu rosto.

Não precisarás mais de rosto.

Nem de suor.

Nem de um corpo.

De hoje em diante

a máquina imperfeita

dos teus músculos

será mais um objeto

em desuso."

(GALVÃO, 2010, p. 55)

La Revista Estudios es editada por la Universidad de Costa Rica y se distribuye bajo una Licencia Creative Commons Atribución-NoComercial-CompartirIgual 3.0 Costa Rica. Para más información envíe un mensaje a 
A poesia de Donizete colhe um país, pois, em guerra contra uma parte consistente de sua população, a mais pobre, a mais precária e impotente. É poesia, essa, que, sem nada perder em qualidade formal e em elaboração estética, é também poesia civil e dialoga conosco e nos interpela. Ela testemunha que estamos num ponto de não retorno, porque não é possível garantir democracia apenas para uma minoria, sem que o próprio sentido do termo "democrático" seja esvaziado por dentro. 


\section{Dossier: Poesía, armonía y conflictos: ayer y hoy}

\section{BIBLIOGRAFIA CONSULTATA}

Agamben, G, (2010). Quel che resta di Auschwitz, Torino; Bollati Boringhieri.

De Alencar, J. (1993). O nosso cancioneiro, estabelecimento do texto e apresentação de Maria E. P. de Freitas, Campinas: Pontes.

De Andrade, O. (1974). Obras Completas VII. Poesias Reunidas, Rio de Janeiro: Civilização Brasileira, 4aㅡ ed.

Bauman, Z. (2011). Vite di scarto, trad. di Marina Astrologo, Bari: Editori Laterza.

Criolo. (2011). “Não existe amor em sp”, Nó na Orelha. O vídeo é produzido por Daniel Ganjaman e Marcelo Cabral, publicado in: https://www.youtube.com/watch?v=f35HluEYpDs

Galvão, D. (1988). Navalha Azul, São Paulo: Edições Excelsior.

- 1990, As faces do rio, São Paulo: Água Viva Edições.

- 1996, Do silêncio da pedra, São Paulo: Arte Pau-Brasil.

- 1997, A carne e o tempo, São Paulo: Nankim.

- 1999, Ruminações, São Paulo: Nankin Editorial.

- 2002, Pelo corpo, em parceria com Ronaldo Polito, Santo André: Alpharrabio.

- 2003, Mundo mudo, São Paulo: Nankin Editorial.

- 2010, O homem inacabado, São Paulo: Portal Editora.

Gonçalves, A. (1974). Ainda uma vez - Adeus (Poemas Escolhidos), Rio de Janeiro: José Aguilar, Brasília: I.N.L.

\section{(c) (i) (-)}

La Revista Estudios es editada por la Universidad de Costa Rica y se distribuye bajo una Licencia Creative Commons Atribución-NoComercial-Compartirlgual 3.0 Costa Rica. Para más información envíe un mensaje a 
Dossier: Poesía, armonía y conflictos: ayer y hoy

lanoni, M, (s.f.) "Plano Temer de Estado mínimo e mercado máximo", in Jornal do Brasil, publicado no web: http://www.jb.com.br/marcus-

Levi, P, Opere - Volume primo, Torino, Einaudi, .

Martins, W. (1968). "A literatura e o conhecimento da terra", in COUTINHO, A. (org. por), A literatura no Brasil, 6 volumes (I), Rio de Janeiro: Editorial Sul Americana.

De Oliveira, V.( 2017). "Habitar as fronteiras", Revista Signótica, Goiânia, v. 29, n.1, pp. 96-105, jan./jun. 2017.

- 2010, O músculo amargo do mundo, São Paulo: Portal Editora.

- 2006, Utopia selvaggia - L'indio del Brasile: innocente Adamo o feroce cannibale?, Roma: Alberto Gaffi Editore.

Ribeiro, D.(1995). O povo brasileiro: a formação e o sentido do Brasil, São Paulo: Companhia das Letras.

- 2010, O Brasil como problema, Rio de Janeiro: Fundação Darcy Ribeiro, Brasília: Editora UnB.

Vecchi, G. (2016) "Il Papa: 'Il mondo è in guerra. Ma sono gli altri a volerla non le religioni, che vogliono la pace'", Corriere della Sera, 28/07/2016, pubblicato in http://www.corriere.it/esteri/16_luglio_27/papa-il-mondoguerra-ma-sono-altri-volerla-non-religioni-che-vogliono-pace-0849e0625402-11e6-bb79-1e466f3b40d8.shtml?refresh_ce-cp

Veloso, C, y Gil, G. (1993). "Haiti”, Tropicália 2, Warner Music Brasil.

\section{(C) $(00)$}

La Revista Estudios es editada por la Universidad de Costa Rica y se distribuye bajo una Licencia Creative Commons Atribución-NoComercial-CompartirIgual 3.0 Costa Rica. Para más información envíe un mensaje a 